\title{
Analysis of the UDP-glucuronosyltransferase gene in Portuguese patients with a clinical diagnosis of Gilbert and Crigler-Najjar syndromes
}

\author{
Elísio Costa ${ }^{\mathrm{a}, *}$, Emília Vieira $^{\mathrm{b}}$, Marcia Martins ${ }^{\mathrm{c}}$, Jorge Saraiva ${ }^{\mathrm{d}}$, Eugénia Cancela ${ }^{\mathrm{e}}$, \\ Miguel Costa ${ }^{\mathrm{f}}$, Roswitha Bauerle ${ }^{\mathrm{g}}$, Teresa Freitas ${ }^{\mathrm{h}}$, João R. Carvalho ${ }^{\mathrm{h}}$, \\ Ermelinda Santos-Silva ${ }^{\mathrm{i}}$, José Barbot ${ }^{\mathrm{j}}$, Rosário dos Santos ${ }^{\mathrm{b}}$ \\ ${ }^{a}$ Escola Superior de Saúde, Instituto Politécnico de Bragança, Avenida D. Afonso V, 5300-121 Bragança, Portugal \\ ${ }^{\mathrm{b}}$ Unidade de Genética Molecular do Instituto de Genética Médica Dr. Jacinto de Magalhães, Portugal \\ ${ }^{\mathrm{c}}$ Consulta do Instituto de Genética Médica Dr. Jacinto de Magalhães, Portugal \\ ${ }^{\mathrm{d}}$ Serviço de Genética do Hospital Pediátrico de Coimbra, Portugal \\ ${ }^{\text {e }}$ Serviço de Gastroenterologia do Hospital de Viseu, Portugal \\ ${ }^{\mathrm{f}}$ Serviço de Gastroenterologia do Hospital de Oliveira de Azeméis, Portugal \\ g Serviço de Medicina Interna do Hospital de Viana do Castelo, Portugal \\ ${ }^{\mathrm{h}}$ Serviço de Gastroenterologia do Centro Hospitalar de Vila Nova de Gaia, Portugal

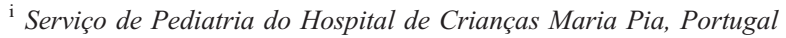 \\ j Serviço de Hematologia do Hospital de Crianças Maria Pia, Portugal
}

Submitted 31 August 2005; revised 2 September 2005

Available online 2 November 2005

(Communicated by E. Beutler, M.D., 6 September 2005)

\begin{abstract}
We describe the molecular study in a cohort of 120 Portuguese patients with the clinical diagnosis of Gilbert syndrome and in one with the diagnosis of Crigler-Najjar syndrome type II, as well as a prenatal diagnosis of Crigler-Najjar syndrome type I. Among the 120 unrelated patients with Gilbert syndrome, 110 were homozygous for the $[\mathrm{TA}] 7$ allele ([TA]7/[TA]7), and one patient was a compound heterozygote for two different insertions ([TA]7/[TA]8). The remaining 9 patients were heterozygous for the TA insertion ([TA]6/[TA]7). Additional studies in these 9 patients revealed heterozygosity for the c.674T $>$ G, c.488_491dupACCT and c.923G $>$ A mutations, in 1, 1 and 4 patients, respectively. The patient with Crigler-Najjar syndrome type II was a compound heterozygote for [TA]7 and the c.923G $>$ A mutation. The undocumented polymorphisms c. $-1126 \mathrm{C}>\mathrm{T}$ and c. $997-82 \mathrm{~T}>\mathrm{C}$ were also detected in the course of this study. Prenatal diagnosis in a family with a boy previously diagnosed as Crigler-Najjar syndrome type I and homozygosity for the c. $923 \mathrm{G}>\mathrm{A}$ mutation revealed that the fetus was unaffected.

Homozygosity for the [TA] insertion was found to be the most frequent cause of GS in our population. Identification of further mutations in the UGT1A1 gene was also seen to contribute significantly towards diagnosis.
\end{abstract}

(C) 2005 Elsevier Inc. All rights reserved.

Keywords: Gilbert syndrome; Crigler-Najjar syndrome; UGT1A1; Hyperbilirubinemia; Mutations

\section{Introduction}

Water-insoluble bilirubin, which results from breakdown products of heme [1-5], is a toxic compound. Hepatic glucuronization of this insoluble bilirubin is catalyzed by isoenzyme 1A1 of UDP-glucuronosyltransferase (UGT1A1), which is essential for efficient biliary excretion of bilirubin [1-

\footnotetext{
* Corresponding author.

E-mail address: elisio.costa@ipb.pt (E. Costa).
}

5]. Genetic alterations causing absence, or severe reduction, of UGT1A1 enzymatic activity result respectively in CriglerNajjar syndrome type I and type II [5-9]. The clinical classification of Crigler-Najjar syndrome types I and II is based on the bilirubin levels, the presence of kernictus and the reduction of the bilirubin levels upon administration of phenobarbital or other enzyme-inducing agents $[4,5,10]$. Mild hyperbilirubinemia, usually less than $50 \mu \mathrm{mol} / \mathrm{L}$, is associated with Gilbert syndrome and thought to reflect a small reduction in UGT1A1 activity (approximately 30\%) [10-12]. Gilbert 
syndrome is characterized by a chronic, nonhemolytic unconjugated hyperbilirubinemia in the absence of liver disease or overt hemolysis $[4,5]$. Serum bilirubin concentration fluctuates during fasting, physical exercise, stress, intermittent illness or menstruation $[4,5,10]$. On the basis of serum bilirubin levels, $3-10 \%$ of the general population is estimated to have Gilbert syndrome $[10,13,14]$.

The UGT1A1 enzyme is encoded by five exons located at the $3^{\prime}$ end of the UGT1A locus and is expressed only in the liver. The first mutation in this gene was described in 1992. It was a nonsense mutation found in homozygosity in a patient with Crigler-Najjar syndrome [6]. Only in 1995 were mutations in this gene found to be correlated with Gilbert syndrome [7]. To date, more than 50 mutations causing Gilbert syndrome and Crigler-Najjar syndrome have been identified, most of which are missense or nonsense mutations, and almost all were first described in association with Crigler-Najjar syndrome. The main cause of Gilbert syndrome in all populations studied to date is a TA insertion in the repetitive TATA-box sequence of the gene promoter, which normally consists of six TA repeats $[9,15-17]$. This [TA]7 allele is extremely common, occurring with an estimated frequency of $38,7 \%$ in the white population and $16 \%$ in the Asian population [9]. In persons with African ancestry, the number of alleles carrying seven or more repeats is reported to be $49.5 \%$ [9]. The TATA-box region is the binding site for the transcription factor IID, thereby playing an important role in the initiation of transcription [7]. A variation in this sequence thus reduces the efficiency and accuracy of gene expression, subsequently leading to higher bilirubin levels $[7,9,18]$.

The phenotypes of Crigler-Najjar syndrome types I and II are usually associated with homozygosity or compound heterozygosity for nonsense and/or missense mutations. A combination of point mutations and abnormal TA repeat numbers in the promoter region of the UGT1A1 gene has also been described in these forms $[10,19,20]$.

Here, the authors describe the molecular study of the UGT1A1 gene in Portuguese patients with the clinical diagnosis of Gilbert syndrome and Crigler-Najjar syndrome.

\section{Material and methods}

\section{Patients}

This study included 120 Caucasian Portuguese patients (77 males and 43 females, aged 12 to 45 years) with the clinical diagnosis of Gilbert syndrome and a further patient with the diagnosis of Crigler-Najjar syndrome type II. Twenty-six of the Gilbert syndrome patients were described previously [17,21]. The diagnoses of Gilbert syndrome and Crigler-Najjar syndrome were based on standard criteria $[4,5,10]$. In the Gilbert syndrome patients, the diagnosis is based by mild hyperbilirubinemia (less than $100 \mu \mathrm{mol} / \mathrm{L}$ ) occurring in the absence of hemolysis or liver disease. The mean total bilirubin concentration of all patients with Gilbert syndrome was 36.02, range 21 to $87 \mu \mathrm{mol} / \mathrm{L}$. The patient with Crigler-Najjar syndrome type II had a basal bilirubin level of $108 \mu \mathrm{mol} / \mathrm{L}$, which decreased with the administration of phenobarbital $(70 \mu \mathrm{mol} / \mathrm{L})$ and increased with fasting $(198 \mu \mathrm{mol} / \mathrm{L})$.

A prenatal diagnosis was also performed for a couple that had a son affected with Crigler-Najjar syndrome type I and homozygosity for the c. $923 \mathrm{G}>\mathrm{A}$ mutation.

\section{Mutation screening}

Genomic DNA was isolated from blood samples using standard methods and from chorionic villi using DNAzol ${ }^{\mathbb{B}}$ reagent (Invitrogen Life Technologies, California, USA).

All patients and 75 healthy Portuguese subjects with no known history of jaundice were screened for the TA insertion in the promoter region of UGT1A1 gene. This TATA-box region was analyzed by PCR amplification using the primers described by Bancroft et al. [32] (UGT1A1-TAF and UGT1A1-TAR from Table 1), with the introduction a fluorochrome label in the reverse primer, for subsequent analysis by automated capillary electrophoresis.

Direct sequencing of the five exons and promoter region (c. -1043 to c. -1568 ) of the UGT1A1 gene was performed in the Gilbert syndrome patients found to be heterozygous for the TA insertion. Table 1 describes the primers designed for the respective PCR amplifications. Sequencing was carried out on the primary amplicons, using the respective forward and reverse primers, in independent sequencing reactions, with the Dye Terminator Cycle Sequencing Kit (Perkin Elmer, Boston, USA) and subsequently resolved on an ABI Prism 310 GeneticAnalyser (Applied Biosystems, Foster City, USA). Sequence analysis was carried out using the reference sequence filed under GenBank accession number 000463.

\section{RFLA}

Restriction fragment length analysis (RFLA) was performed for carrier detection of the c.923G $>$ A mutation and population

Table 1

Primers used in the amplification of the UGT1A1 exons and promoter region

\begin{tabular}{lll}
\hline $\begin{array}{l}\text { UGT1A1 } \\
\text { region }\end{array}$ & Primer name & Primer sequence \\
\hline Promoter & UGT1A1-PF & 5'CTCTAAGCACATCCCCAAGTA ${ }^{\mathrm{a}}$ \\
& UGT1A1-PR & 5'TAAGCAAGTTTCCATCCTTCA ${ }^{\mathrm{a}}$ \\
& UGT1A1-TAF & 5'TAACTTGGTGTATCGATTGGTTTTG \\
& UGT1A1-TAR & 5'ACAGCCATGGCGCCTTTGCT \\
Exon 1 & UGT1A1-1aF & 5'AGGAGCAAAGGCGCCATGGC \\
& UGT1A1-1aR & 5'TGCAGTAAGTGGGAACAGCC \\
& UGT1A1-1bF & 5'GCTGTTCCCACTTACTGCACA \\
& UGT1A1-1bR & 5'CGCATGTAAAAGTCCCACTCC \\
Exon 2 & UGT1A1-2F & 5'TCTATCTCAAACACGCATGCC \\
& UGT1A1-2R & 5'GGCAGGGAAAAGCCAAATCTA \\
Exon 3 & UGT1A1-3F & 5'TTGCCAGTCCTCAGAAGCCTT \\
& UGT1A1-3R & 5'ATGCCCTTGCAGAAATTGC \\
Exon 4 & UGT1A1-4F & 5'TGCAAGGGCATGTGAGTAACA \\
& UGT1A1-4R & 5'AAGCCAAGATTGCACCACTG \\
Exon 5 & UGT1A1-5F & 5'GAGGATTGTTCATACCACAGG \\
& UGT1A1-5R & 5'GCACTCTGGGGCTGATTAAT
\end{tabular}

\footnotetext{
${ }^{\text {a }}$ From Ref. [18].

b Fluorochrome labeled primer (Ned).
} 
screening of the new c. $-1126 \mathrm{C}>\mathrm{T}$ variation. Samples of the PCR amplicons of exon 2 and the promoter region were directly digested with HinfI and Cac8I enzymes respectively, and the products resolved by electrophoresis on a $4 \%$ agarose gel.

$\operatorname{SSCA}$

Single-strand conformational analysis (SSCA) was performed for carrier detection of the c.674T $>\mathrm{G}$ mutation and for carrier and population screening of the c.488_491dupACCT and c.997-82T>C variations. Amplicons of exon 1 (c.488_491dupACCT and c.674T $>\mathrm{G}$ ) and exon 3 (c.997-82T $>$ C) were electrophoresed at room temperature on $0.5 \times$ MDE gels (BMA Products, Nottingham, UK) and visualized by conventional silver staining methods.

The population screen was carried out on 100 samples from normal individuals.

\section{Results}

\section{Mutation analysis}

Among the 120 unrelated patients with Gilbert syndrome, 110 were homozygous for the $[\mathrm{TA}] 7$ allele ([TA]7/[TA $] 7)$ and 9 were heterozygous ([TA]6/[TA]7). One patient was a compound heterozygote for two insertions, namely $[\mathrm{TA}] 7 /[\mathrm{TA}] 8$ (Fig. 1). Among 75 healthy subjects, 5 were homozygous for the [TA]7 allele, 40 were homozygous for the [TA] 6 allele, and 29 were heterozygous. The remaining subject was compound heterozygote for the [TA]5 and [TA]7 alleles.

Additional studies performed on the 9 GS patients seen to be heterozygous for the [TA]7 allele revealed compound heterozygosity with the c.923G>A (Gly308Glu) mutation in four patients (Fig. 2). In another patient, the [TA]7 allele was found to be associated in cis with the c.674T $>\mathrm{G}$ (Val225Gly) mutation (Fig. 3). A further patient revealed heterozygosity

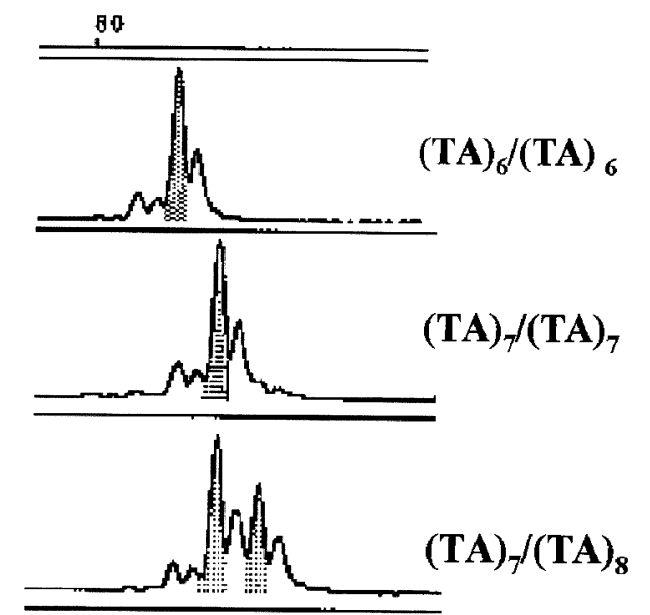

Fig. 1. The amplified DNA fragment was separated by automated capillary electrophoresis and analyzed with ABI GeneScan program (Applied Biosystems). (A) Homozygosity for the normal (TA)6 allele; (B) homozygosity for a mutant (TA)7 allele; (C) our patient with (TA)7 and (TA) 8 alleles.
A
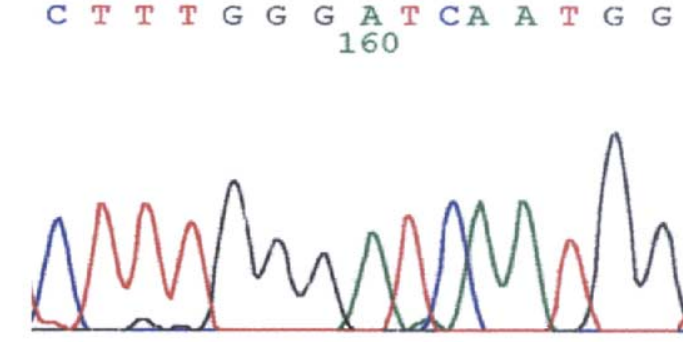

B
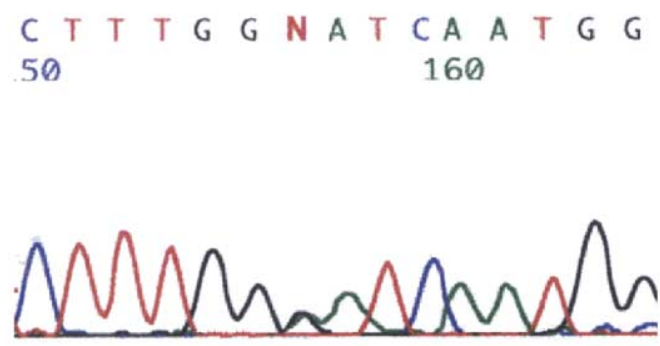

C

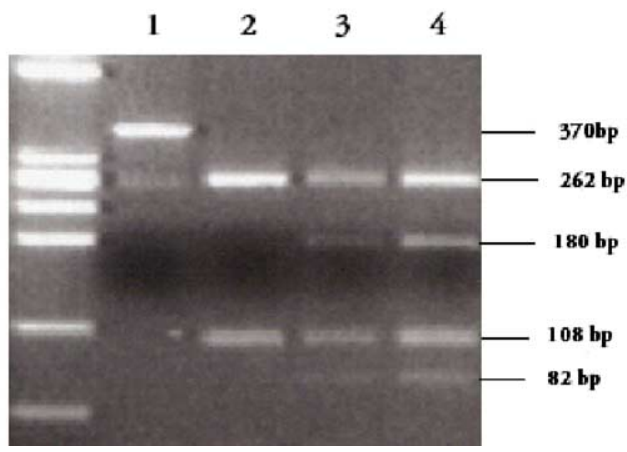

Fig. 2. Partial sequence around the c. $923 \mathrm{G}>\mathrm{A}$ mutation site in exon 2 of the UGT1A1 gene. (A) Normal sequence. (B) Heterozygous patient. (C) Restriction analysis of c.923G $>$ A, using Hinfl. Lane 1-undigested fragment; lane 2-normal individual; lanes 3 and 4-heterozygous patients.

for the c.488_491dupACCT mutation (Fig. 4). This previously not described mutation was not detected in 100 unrelated control individuals. In this case, the family study was not possible, and it therefore remains unknown if the two alterations are allelic. In the remaining three $[\mathrm{TA}] 7$ heterozygotes patients, no mutations were detected.

The patient with Crigler-Najjar syndrome type II was also a compound heterozygote for the (TA) insertion and the c. $923 \mathrm{G}>$ A mutation. Direct sequencing of the UGT1A1 gene in this patient failed to reveal additional alterations.

Additionally, we found two polymorphisms in the UGT1A1 gene, one in the promoter region (c. $-1126 \mathrm{C}>\mathrm{T}$ ) and the other in intron 2 (c. $997-82 \mathrm{~T}>\mathrm{C}$ ). The first was found in $4 \%$ and the second in $30 \%$ of the 100 control individuals.

In the prenatal diagnosis, the familial c. $923 \mathrm{G}>\mathrm{A}$ mutation was not detected in the DNA sample obtained from chorionic villi. Maternal contamination was excluded in the fetal sample using microsatellite markers D5S640, D5S2077, D5S673, D5S410, D13S232, D13S292, D13S1243，D13S1285, DMDSTR44, DMDSTR45, DMDSTR49 and DMDSTR50. Heterozygosity for c. $923 \mathrm{G}>\mathrm{A}$ was confirmed in both parents and for the (TA) insertion in the fetus and in the mother. 
A

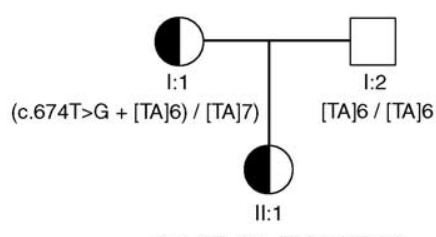

(c.674T $>\mathrm{G}+[\mathrm{TA}] 6) /[\mathrm{TA}] 7)$

B

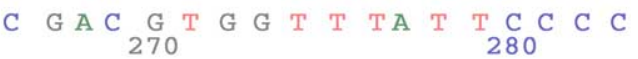

C
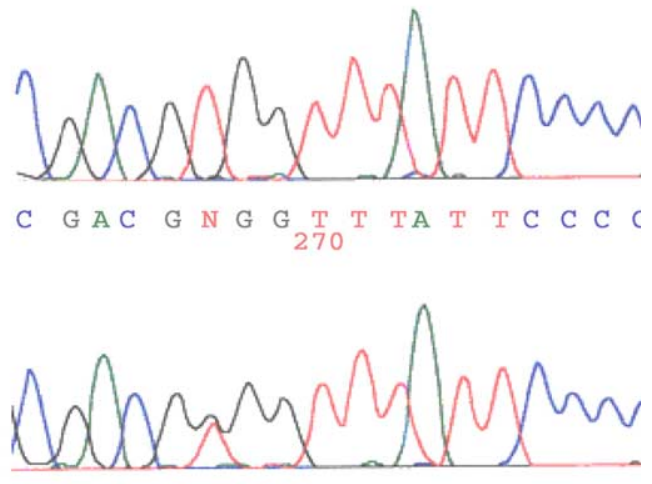

D

1

2

3

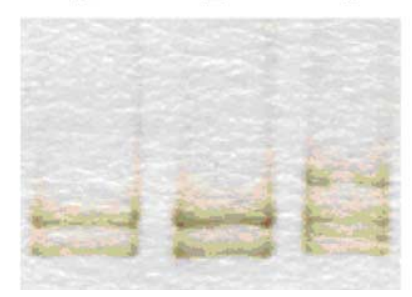

Fig. 3. Nucleotide sequence of a part of exon 1 of the UGT1A1 gene. (A) Family study of the patients with the c.674T $>\mathrm{G}$ and [TA]7 mutations. (B) Normal sequence. (C) Patient heterozygous for the c.674T $>\mathrm{G}$ mutation. (D) SSCA. Lanes 1 and 2-normal individuals; lane 3-heterozygous patient.

\section{Genotype/phenotype correlations and family studies}

In the four Gilbert syndrome patients with TA insertion and c. $923 \mathrm{G}>$ A mutations, the average of bilirubin was $61.3 \mu \mathrm{mol} / \mathrm{L}$ (SD: $23.6 \mu \mathrm{mol} / \mathrm{L}$ ), which was higher than that found in Gilbert syndrome patients with other genotypes (Table 2).

The mean total bilirubin level found in male patients homozygous for the TA insertion was compared by MannWhitney test and was statistically higher $(P=0.008)$ than that of female patients with the same genotype $(39.6 \mu \mathrm{mol} / \mathrm{L}$ [SD: $24.07 \mu \mathrm{mol} / \mathrm{L}$ ] versus $26.96 \mu \mathrm{mol} / \mathrm{L}$ [SD: $10.98 \mu \mathrm{mol} / \mathrm{L}])$ (Fig. 5).

In three of the four Gilbert syndrome cases presenting heterozygosity for the c. $923 \mathrm{G}>\mathrm{A}$ mutation, the parents were seen to have normal bilirubin levels. Molecular analysis revealed heterozygosity for the point mutation in the mother and heterozygosity for (TA) insertion in the father, in all three cases. In the fourth family, the mother and a maternal uncle had high bilirubin levels ( 41 and $35 \mu \mathrm{mol} / \mathrm{L}$, respectively). Here, the mother was found to be compound heterozygous for c. $923 \mathrm{G}>\mathrm{A}$ and the (TA) insertion, whereas the uncle was homozygous for [TA]7. The father, however, who was also homozygous for $[\mathrm{TA}] 7$, presented normal bilirubin levels $(15 \mu \mathrm{mol} / \mathrm{L})$.
In the Gilbert syndrome patient with the c.674T $>\mathrm{G}$ mutation, both this and the (TA) insertion were found in the mother and neither were found in the father, thereby placing the two alterations in cis. However, bilirubin levels were normal in the mother, who had no history of intermittent jaundice.

Analysis of the Gilbert syndrome patient with the [TA]7/ [TA]8 genotype revealed that the father carried the [TA]8 allele, and the mother carried the [TA]7 allele. Both parents had normal bilirubin levels.

The mother of the Crigler-Najjar syndrome patient presented slight hyperbilirubinemia $(22 \mu \mathrm{mol} / \mathrm{L})$ and was homozygous for the $[\mathrm{TA}] 7$ allele. The father had normal bilirubin levels and was heterozygous for the c.923G $>$ A mutation.

\section{Discussion}

Traditionally, Gilbert syndrome has been a diagnosis of exclusion. Routine biochemical measurement of enzymatic activity has never been routinely possible, but genetic testing for Gilbert syndrome has the potential to provide a positive diagnosis. Genetic testing also aids in patient management, since undiagnosed Gilbert syndrome patients are often subjected to invasive investigations prompted by the finding of jaundice $[4,5,10]$.

The (TA) insertion in the promoter region of the UGT1A1 gene was seen to be the main cause of Gilbert syndrome in Portuguese population. This high frequency is similar to that found in other populations. Based on the frequency observed in Caucasians, in several studies of smaller series, Beutler et al. [9] calculated a homozygote frequency of $15 \%$. This predicted value is higher than that of patients with a clinical diagnosis of Gilbert syndrome, reflecting the existence of other inherited or acquired factors affecting bilirubin metabolism, in addition to reduced glucuronidation caused by the (TA) insertion. The awareness that the (TA) insertion is the most frequent cause of Gilbert syndrome prompted the study of its association with other pathologies, namely $\beta$-thalassemia [22,23], sickle cell anemia [24], ABO incompatibility [25], glucose-6-phosphate dehydrogenase deficiency [26-28], hereditary spherocytosis [29,30,31] and neonatal icterus $[32,33]$.

Our male patients who were homozygous for the longer TATAA element had a more significant increased in serum bilirubin than females (1.5 times). This may reflect the greater bilirubin load per kilogram of body weight males or the inhibition of enzymatic glucuronidation by endrogenic steroids or both [7]. These higher levels may also explain the sample bias of 2:1 (men:women) in our group of Gilbert syndrome patients.

In Caucasian populations, the [TA]8 allele is extremely rare [34,35]. However, in African populations, this allele is somewhat more common, with a frequency of $6.9 \%$ [9]. The presence of this rare allele in Caucasian was suggested by Iolascon et al. [34] and Tsezou et al. [35] to be a result of a recent genetic event and not derived from a common ancestral mutation. In effect, repeated sequences are extremely unstable 


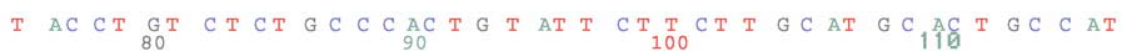

A

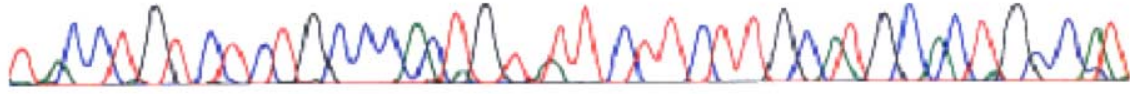

T A C T T T CTCT G C C ACT G T AT T T T CT T G CA T

B

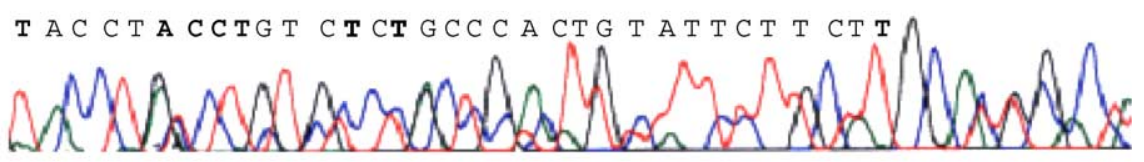

C

1

2

3

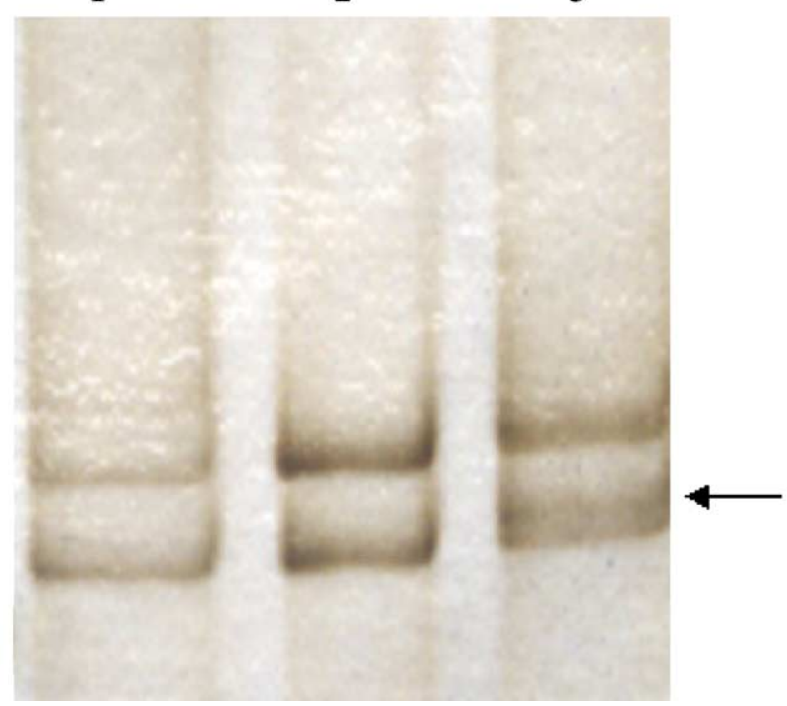

Fig. 4. Partial nucleotide sequence around the c.488_491dupACCT mutation in exon 1 of the UGT1A1 gene. (A) Normal sequence. (B) Heterozygous patient. (C) SSCA. Lanes 1 and 2-normal individuals; lane 3-heterozygous patient.

and may be lengthened or shortened by a variety of mechanisms, such as unequal crossing over in meiosis. The compound heterozygote in the present study ([TA]7/[TA]8) is very similar, to the case described by Iolascon et al. [34], in terms of age, gender and bilirubin levels, providing evidence for some degree of correlation between phenotype and genotype. The production of mRNA decreases progressively as the number of repeats increases [9]. For this reason, our patient could have a more severe phenotype than the patients homozygous for the $[\mathrm{TA}] 7$ allele.

Table 2

Relationship between total bilirubin levels and genotypes

\begin{tabular}{lllll}
\hline Patients & Phenotype & Allele 1 & Allele 2 & $\begin{array}{l}\text { Bilirubin } \\
\text { levels }(\mu \mathrm{mol} / \mathrm{l}) \\
(\mathrm{mean} \pm \mathrm{SD})\end{array}$ \\
\hline 110 & GS & {$[\mathrm{TA}] 7$} & {$[\mathrm{TA}] 7$} & $32.12 \pm 18.1$ \\
4 & GS & {$[\mathrm{TA}] 7$} & c.923G $>$ A & $61.3 \pm 23.6$ \\
1 & GS & {$[\mathrm{TA}] 7+\mathrm{c} .674 \mathrm{~T}>\mathrm{G}$} & - & 48 \\
1 & GS & {$[\mathrm{TA}] 7+$} & & 39 \\
& & c.488_491dupACCT & & \\
1 & GS & {$[\mathrm{TA}] 7$} & {$[\mathrm{TA}] 8$} & 60 \\
1 & CNS & {$[\mathrm{TA}] 7$} & c.923G $>$ A & 108 \\
3 & GS & {$[\mathrm{TA}] 7$} & $?$ & $46.6 \pm 29.95$ \\
\hline
\end{tabular}

GS-Gilbert Syndrome, CNS-Crigler-Najjar Syndrome.

${ }^{a}$ Family study was not possible.

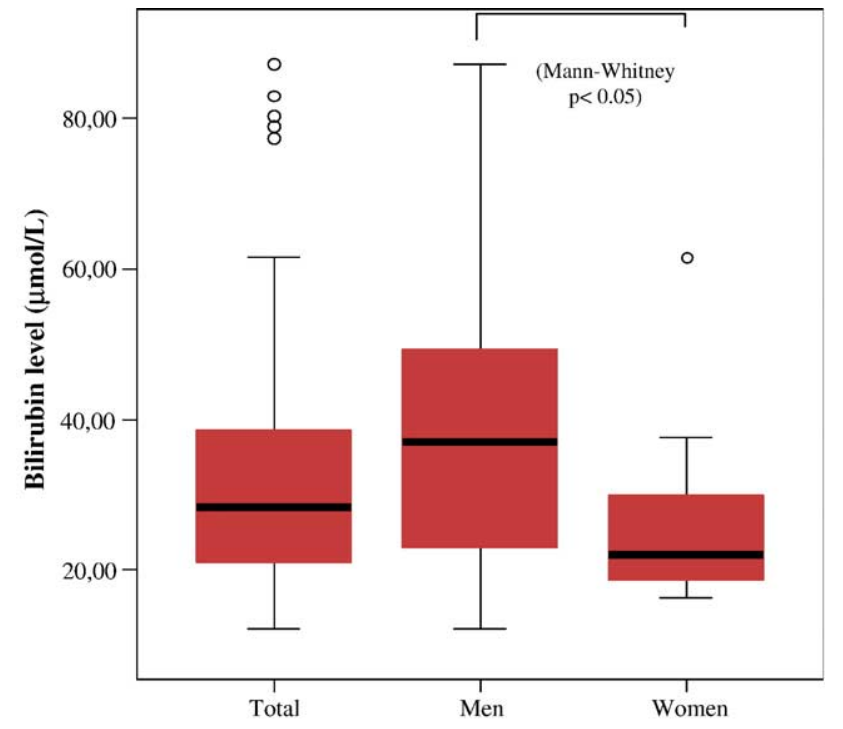

Fig. 5. Comparison of bilirubin levels among the total of patients and in male and female patients, homozygous for the TA insertion. The box has an upper and lower edge at 25th and 75th percentiles. The lines inside the boxes represent median (50th percentile). The lines that are drawn from the box represent the upper and lower limits. The circles represent the outlier values. 
Erps et al. [36] first described the c. $923 \mathrm{G}>\mathrm{A}$ mutation in a 7-year-old female with Crigler-Najjar syndrome type I. This mutation, coincident with a highly conserved residue in the protein sequence, results in the lack of enzyme activity. The authors identified heterozygosity for this mutation in both parents and in one brother but did not refer to her bilirubin levels. Surprisingly, this was found to be the second most frequent mutation associated with Gilbert syndrome in our population, in each case always in compound heterozygosity with the (TA) insertion. Screening for this mutation therefore seems important in Portuguese patients with Gilbert syndrome.

Compound heterozygosity for c. $923 \mathrm{G}>\mathrm{A}$ and the (TA) insertion was also found in our patient with Crigler-Najjar syndrome type II. No reference was found in the literature of this combination associated with Crigler-Najjar syndrome type II. Usually the phenotype of Crigler-Najjar syndrome type II is associated with homozygosity or compound heterozygosity for missense mutations. However, more rarely, intermediate levels of hyperbilirubinemia have been observed in heterozygote carriers of Crigler-Najjar syndrome type I mutations who also carry a (TA) insertion in the second allele $[38,39]$. The presence of this compound heterozygosity was found in both Gilbert syndrome and Crigler-Najjar syndrome patients, once again pointing towards the existence of other inherited and/or acquired factors affecting bilirubin levels.

Iolascon et al. [37] described a case of Crigler-Najjar syndrome type II which is result of interaction of c.674T $>\mathrm{G}$ and c.239_240delAG mutations and homozygosity for the (TA) insertion. This patient inherited the c.674T $>\mathrm{G}$ mutation from his mother, which is also heterozygotic to the (TA) insertion. Like in our patient and his mother, she has the two mutations in the same chromosome. The bilirubin level, found in mother of our patient and in the mother of the patient described by Iolascon et al. [37], were normal or slightly elevated $(15$ and $18.7 \mu \mathrm{mol} / \mathrm{L}$ respectively). We think this is a causal mutation because the valine residue is highly conserved, none of 100 unrelated control individuals was found to carry the mutation, and direct sequencing of UGT1A1 gene in our patient does not detect the presence of additional alterations.

The c.488_491dupACCT mutation was described for the first time in the present study. This frameshift mutation results in a premature stop codon at nucleotide 183. The drastic alteration at polypeptide level, as well as the fact that this mutation was not found in the 100 unrelated control individuals, provides strong evidence that this alteration is responsible for the Gilbert syndrome phenotype of the patient.

In conclusion, the (TA) insertion was found to be present in all of our cases and is thus the most frequent cause of Gilbert syndrome in our population. Other alterations in the UGT1A1 gene were also seen to be associated with Gilbert syndrome; in particular, the c. $923 \mathrm{G}>\mathrm{A}$ mutation seems to be recurrently associated with hyperbilirubinemia. Identification of this and other mutations in the UGT1A1 gene could therefore also contribute significantly towards diagnosis, genetic counseling and prenatal diagnosis.

\section{References}

[1] R. Schmid, Some aspects of the bile pigment metabolism, Clin. Chem. 3 (1957) 394-400.

[2] R. Schmid, Direct-reacting bilirubin glucuronide, in serum, bile, and urine, Science 124 (1956) 76-77.

[3] B.H. Biling, P.G. Cole, G.H. Lathe, The excretion of bilirubin as diglucuronide giving the direct van den Bergh reaction, Biochem. J. 65 (1957) $774-784$.

[4] G.R. Lee, T.C. Bithell, J. Foerster, J.W. Athens, J.N. Lukens, Wintrobe's Clinical Haematology, 9th ed., Lea and Febiger, Philadelphia, 1993.

[5] D.G. Nathan, S.H. Orking, Nathan and Oski's Haematology of Infancy and Childhood, 5th ed., WB Sanders Company, Philadelphia, 1998.

[6] P.J. Bosma, N.R. Chowdhury, B.G. Goldhoorn, et al., Sequence of exons and the flanking regions of human bilirubin-UDP-glucuronosyltransferase gene complex and identification of a genetic mutation in a patient with Crigler-Najjar syndrome type I, Hepatology 15 (1992) 941-947.

[7] P.J. Bosma, J.R. Chowdhury, C. Bakker, S. Gantla, et al., The genetic basis of the reduced expression of bilirubin UDP-glucuronosyltransferase 1 in Gilbert's syndrome, N. Engl. J. Med. 333 (1995) 1171-1175.

[8] B. Burchell, R. Hume, Molecular genetic basis of Gilbert's syndrome, J. Gastroenterol. Hepatol. 14 (1999) 960-966.

[9] E. Beutler, T. Gelbart, A. Demina, Racial variability in the UDPglucuronosyltransferase 1 (UGT1A1) promoter: a balanced polymorphism for regulation of bilirubin metabolism? Proc. Natl. Acad. Sci. U. S. A. 95 (1998) 8170-8174.

[10] M. Sampietro, A. Iolascon, Molecular pathology of Crigler-Najjar type I and II and Gilbert's syndrome, Haematologica 84 (1999) 150-157.

[11] I.M. Arias, I.M. London, Bilirubin glucuronide formation in vitro; demonstration of a defect in Gilbert's disease, Science 126 (1957) $563-564$

[12] M. Black, B.H. Billing, Hepatic bilirubin UDP-glucuronosyltransferase activity in liver disease and Gilbert's syndrome, N. Engl. J. Med. 280 (1969) 1266-1271.

[13] A. Sieg, L. Arab, G. Schlierf, A. Stiehl, B. Kommerell, Prevalence of Gilbert's syndrome in Germany, Dtsch. Med. Wochenschr. 112 (1987) 1206-1208.

[14] D. Owens, J. Evans, Population studies on Gilbert's syndrome, J. Med. Genet. 12 (1975) 152-156.

[15] M.L. Biondi, O. Turri, D. Dilillo, G. Stival, E. Guagnellini, Contribution of the TATA-box genotype (Gilbert syndrome) to serum bilirubin concentrations in Italian population, Clin. Chem. 45 (1999) 897-898.

[16] D. Pirulli, M. Giordano, D. Puzzer, S. Crovella, I. Rigato, C. Tiribelli, et al., Rapid method for detection of extra (TA) in the promoter of the bilirubinUDP-glucuronosyl transferase 1 gene associated with Gilbert syndrome, Clin. Chem. 46 (2000) 129-131.

[17] E. Costa, E. Vieira, E. Santos-Siva, et al., TATA-box polymorphism in the uridine diphosphate glucuronosyl transferase gene in Portuguese patients with a clinical diagnosis of Gilbert's syndrome, Haematologica 87 (04) (2002) ELT21.

[18] H. Ueyama, O. Koiwai, Y. Soeda, H. Sato, Y. Satoh, I. Ohkubo, Y. Doida, Analysis of the promoter of human bilirubin UDP-glucuronosyltransferase gene $(\mathrm{UGT} 1 * 1)$ in relevance to Gilbert's syndrome, Hepatol. Res. 9 (1997) $152-163$

[19] N. Chalasani, N.R. Chowdhury, J.R. Chowdhury, T.D. Boyer, Kernicterus in an adult who is heterozygous for Crigler-Najjar syndrome and homozygous for Gilbert type genetic defect, Gastroenterology 112 (1997) 2099-2103.

[20] K. Yamamoto, Y. Soeda, T. Kamisako, et al., Analysis of bilirubin uridine 5 -diphosphate (UDP)-glucuronosyltransferase gene mutations in seven patients with Crigler-Najjar syndrome type II, J. Hum. Genet. 43 (1998) $111-114$

[21] H. Coelho, E. Costa, E. Vieira, R. Branca, R. dos Santos, J. Barbot, A new case of (TA) 8 allele in the UGTA1 gene promoter in a Caucasian girl with Gilbert's syndrome, Pediatr. Hematol. Oncol. 21 (2004) 371-374.

[22] R. Galanello, L. Perseu, M.A. Melis, L. Cipollina, S. Barella, N. Giagu, M.P. Turco, O. Maccioni, A. Cao, Hyperbilirubinaemia in heterozygous 
beta-talassaemia is related to co-inherited Gilbert's syndrome, $\mathrm{Br}$. J. Haematol. 99 (1997) 433-436.

[23] C. Borgna-Pignatti, F. Rigon, L. Merlo, et al., Thalassemia minor, the Gilbert mutation, and risk of gallstones, Haematologica 88 (2003) 1106-1109.

[24] R.G. Passon, T.A. Howard, S.A. Zimmerman, W.H. Schultz, R.E. Ware, Influence of bilirubin uridine diphosphate glucuronosyltransferase 1A promoter polymorphisms on serum bilirubin levels and colelithiasis in children with sickle cell anemia, J. Pediatr. Hematol. Oncol. 23 (2001) 448-451.

[25] M. Kaplan, C. Hammarman, P. Renbaum, G. Klein, E. Levy-Lahad, Gilbert's syndrome and hyperbilirubinaemia in ABO-incompatible, Lancet 356 (2000) 652-653.

[26] M. Kaplan, E. Beutler, H.J. Vreman, C. Harmmerman, E. Levy-Lahad, P. Renbaum, D.K. Stevenson, Neonatal hyperbilirubinemia in glucose-6phosphate dehydrogenase deficient heterozygotes, Pediatrics 104 (1999) $68-74$.

[27] E. Costa, E. Vieira, E. Cleto, et al., Glucose-6-phosphate dehydrogenase deficiency, neonatal hyperbilirubinemia and Gilbert syndrome, Acta Med. Port. 15 (2002) 409-412.

[28] A. Iolascon, M.F. Faienza, L. Giordani, S. Perrotta, G. Ruggiu, G.F. Meloni, E.M. del Giudice, Bilirubin levels in the acute hemolytic crisis of G6PD deficiency are related to Gilbert's syndrome, Eur. J. Haematol. 62 (1999) 307-310

[29] E.M. Giudice, S. Perrota, B. Nobili, C. Specchia, G. d'Urzo, A. Iolascon, Coinheritance of Gilbert syndrome increases the risk for developing gallstones in patients with hereditary spherocytosis, Blood 94 (1999) 2259-2262.

[30] R.F. Schilling, Sherocytosis, splenectomy, stroke, and heart attacks, Lancet 350 (1997) 1677-1678.
[31] E. Costa, R. Pinto, E. Vieira, et al., Influence of Gilbert's syndrome on serum bilirubin levels and gallstone formation in children with chronic hemolytic disease, An. Esp. Pediatr. 57 (2002) 529-533.

[32] J.D. Bancroft, B. Kreamer, G.R. Gourley, Gilbert syndrome accelerates development of neonatal jaundice, J. Pediatr. 132 (1998) 656-660.

[33] A.M. Alexandrino, C. Carvalho, E. Costa, E. Vieira, P. Oliveira, C. Duarte, J. Barbot, R. dosSantos, A. Areias, TATA box polymorphism in the UDP-glucoronosyltransferase 1 gene promoter and neonatal hyperbilirubinemia, Prenat. Neonatal Med. 6 (2001) 133-136.

[34] A. Iolascon, M.F. Faienza, M. Centra, S. Storelli, et al., (TA) 8 allele in the UGT1A1 gene promoter of a Caucasian with Gilbert's syndrome, Haematologica 84 (1999) 106-109.

[35] A. Tsezou, M. Tzetis, S. Kitsiou, et al., A Caucasian boy with Gilbet's syndrome heterozygous for the (TA) 8 allele, Haematologica 85 (2000) 319.

[36] L.T. Erps, J.K. Ritter, J.H. Hersh, D. Blossom, N.C. Martin, I.S. Owens, Identification of two single base substitutions in the UGT1 gene locus which abolish bilirubin uridine diphosphate glucuronosyltransferase activity in vitro, J. Clin. Invest. 93 (1994) 564-570.

[37] A. Iolascon, A. Meloni, B. Coppola, M.C. Rosatelli, Crigler Najjar type II due to three different mutations in the bilirubin uridine $5^{\prime}$ diphosphate glucuronosyltransferase (UGT1A) gene, J. Med. Genet. 37 (2000) 712-713

[38] M. Ciotti, F. Chen, F.F. Rubaltelli, I.S. Owens, Coding defect and a TATA box mutation at the bilirubin UDP-glucuronosyltransferase gene cause Crigler-Najjar type I disease, Biochim. Biophys. Acta 1407 (1998) 40-50.

[39] A. Kadakol, S.S. Ghosh, B.S. Sappal, G. Sharma, J.R. Chowdhury, N.R. Chowdhury, Genetic lesions of bilirubin uridine diphosphate glucuronosyltransferase (UGT1A1) causing Crigler-Najjar and Gilbert syndromes: correlation of genotype to phenotype, Hum. Mutat. 16 (2000) 297-307. 